\title{
IDEOLOGIAS E A PRÁXIS DE ENSINO DE EDUCAÇÃO AMBIENTAL CRÍTICA ESCOLAR
}

\author{
Magno da Conceição Peneluc ${ }^{1}$ \\ Edilson Fortuna de Moradillo²
}

Resumo: O presente artigo investigou, no âmbito da formação inicial de professores, como ideologias capitalistas interferem em práxis educacionais relativas à Educação Ambiental Crítica (EAC) escolar. Investigou-se como as ideologias relativas à água enquanto recurso socioambiental, a qual é concebida pela sociedade como repleta de objetivações relacionadas à ética e à lógica capitalista, podem ser relevantes em práxis pedagógicas. As ideologias não tratam necessariamente de representações deturpadas da realidade; mas estão sempre relacionadas a dadas práticas sociais que definem a ação dos indivíduos, e instrumentalizam o ser social em sua ação política.

Palavras-chave: Educação Ambiental Crítica; Ideologia; Formação de Professores.

${ }^{1}$ Rede de educação do estado de Sergipe. E-mail: bio.magno@gmail.com

2Universidade Federal da Bahia. E-mail: edilson@ufba.br 


\section{Introdução}

O Brasil tem se pautado numa agenda retrógrada quando se trata de educação pública, adotando de forma unidimensional e acrítica pedagogias alinhadas com o paradigma conservador. Isto tem levado à renúncia da crítica social e das discussões acerca da relação entre trabalho e educação, o que resulta na ausência de teorizações sobre o papel da educação como meio de emancipação e de formação do ser social integral. Em decorrência, questionamos até que ponto ideologias capitalistas cumprem um papel conservador e potencializador do status quo que caracteriza nossa educação como reprodutora mecânica de competências e habilidades demandadas pelo capitalismo. O presente artigo, considerando este contexto, investigou - no âmbito escolar da formação inicial de professores-, como ideologias capitalistas interferem em práxis educacionais relativas à Educação Ambiental Crítica (EAC) escolar.

No tocante às relações de produção, o capital necessita de uma superestrutura política, educacional, jurídica, ideológica e institucional que viabilize as relações entre os capitalistas e os trabalhadores. O processo produtivo neste sistema só funciona a uma taxa produtiva sempre crescente, o que demanda em excesso os meios de produção, bem entendido, os recursos naturais e o trabalho humano. Este é o cerne crítico da EAC: compreender como se dá historicamente as relações dos seres humanos com a natureza neste modo de produção e explicitar quais são as consequências, com vistas à mudança socioambiental e cultural. O conceito de meio ambiente surge para estipular as especificidades sociais (cultural, tecnológica, científica e econômica, em termos de ocupação e alteração espacial) da relação que a sociedade mantém com a natureza (LAYRARGUES, 2006; LOUREIRO et. al., 2009).

Vaisman (2010) esclarece que só no momento de sua concretização no seio da sociedade é que um determinado enunciado pode ser considerado como ideológico, ao se tornar veículo teórico/prático, constitui-se como préviaideação e concretização da prática social dos homens. Contextualizadas no universo da educação formal, em sala de aula, questiona-se até que ponto superestruturas ideológicas interferem no processo de ensino. No tocante às ideologias operantes na história contemporânea da sociedade capitalista, interessou a presente pesquisa investigar as ideologias relativas à água enquanto recurso socioambiental, a qual é concebida pela sociedade como repleta de objetivações relacionadas à ética e à lógica capitalista. Optou-se pela água por ser um recurso natural que além de ser decisivo aos processos de vida - considerando também as condições sociais de vivência -, tem se intensificado conflitos em torno da apropriação/utilização da água, seja como recurso/meio de produção e meio de dispersão de poluentes, seja como elemento básico da dessedentação e manutenção da saúde humana. A água, por fim, é um componente da realidade socioambiental de alta relevância, o que confere seu caráter pedagógico, pois é um elemento insopitável que faz parte da realidade social (ou socioambiental), o qual deve ser assumido como

revista brasileira educação ambiental 
conteúdo a ser mediado ao universo escolar, considerando os princípios pedagógicos da Pedagogia Histórico-crítica (PHC).

A presente pesquisa deu especial ênfase à discussão sobre a relevância que as ideologias possuem sobre práxis pedagógicas escolares. Cabe esclarecer que o objetivo norteador da pesquisa foi buscar compreender como ideologias interferem em processos de ensino formal. Contudo, para que fosse alcançado tal intento, foi necessário realizar primeiramente a identificação e a descrição destas ideologias que estão presentes na práxis dos estudantes, quais são as categorias que compõem estas estruturas ideológicas e como elas repercutem em comportamentos e ações destes sujeitos sociais. Identificaram-se as ideologias e foi descrito como as ideologias interveem em práxis pedagógicas. Foi necessário inicialmente que se explicitasse as noções de ser humano, de sociedade, de natureza, de indivíduo e de modo produção. Posteriormente foi proposta uma intervenção didática que buscou alterar as ideologias subliminares à prática social de sujeitos sociais participantes da fase empírica da pesquisa.

O materialismo histórico-dialético foi assumido enquanto base teóricometodológica para a análise da realidade histórica da sociedade e do caráter político e econômico da crise socioambiental. Neste sentido, a dialética materialista histórica marxiana perfaz um aparato teórico que abarca e explicita a historicidade das relações ser humano/natureza. A intensão desta pesquisa foi, além de compreender como ideologias interferem em processos de ensino, realizar uma teorização a cerca de possíveis práxis pedagógicas que intencionalmente promovam a alteração destas mesmas ideologias.

Questionou-se como as ideologias se relacionam com a educação, especificamente em seu aspecto pedagógico, no que se refere à relação professor-estudante. Em decorrência se fez necessário identificar quais são estas ideologias, como interferem no processo de ensino de conteúdos relativos à EAC, quais são as ideias, conceitos e valores que compõem as estruturas ideológicas dos estudantes e como elas repercutem em comportamentos e ações destes sujeitos sociais relativos à água. Este problema nos conduziu a propor uma intervenção didática no contexto da formação inicial de professores numa turma da disciplina "O Professor e o Ensino de Química" do curso de Licenciatura em Química da Universidade Federal da Bahia (Ufba). A intervenção se concretizou por meio de uma práxis pedagógica que buscou promover a alteração destas ideologias, no sentido de um projeto emancipatório de educação que busca superar a ética e a lógica do capitalismo. A proposta intervenção foi centrada no âmbito da formação inicial de professores e se destinou ao escopo da EAC, tendo como suporte teórico a PHC. 


\section{Ideologia e educação}

Enquanto um fenômeno social relevante, grande parte de filósofos e cientistas sociais sustentaram que as ideologias têm assumido um propósito eminentemente de dissimulação da realidade, de distorção, de alienação; até mesmo de ocultamento da realidade e sua transformação em "verdade" universal. Esta acepção está clara em Marx e Engels no livro A ideologia alemã (1982), ao se referirem à ideologia como parte da relação de mútuo condicionamento entre homem e natureza, acabando por resultar em deturpação ou mascaramento da realidade. Esta função emerge em um contexto histórico conflitivo, em uma sociedade fundada sob o modo de produção capitalista, na qual o capital necessita de uma organização social que o retroalimente, daí a função relevante da ideologia: legitimar, dar contornos identificáveis e aparentemente familiares, mas que na verdade acobertam a realidade das relações sociais, tais são funções inegáveis que as ideologias têm assumido em sociedades marcadas pela luta de classes. Inegável é que as classes dominantes usam e abusam de ideologias que ampliam a alienação nascente nas relações materiais, distorcem o que realmente ocorre no seio das relações sociais capitalistas. Todavia, surge uma pergunta que não quer calar: será este o único status epistemológico (de enunciado teoricamente falso) e função social negativa da ideologia, ou esta possui outros sentidos valorativos e outros papéis sociais - dependendo de qual classe social se aproprie, de como esta ideologia é construída no processo discursivo e de como (quais as intenções veladas ou explícitas) esta classe social usa a ideologia? Ou ainda, não seria mais adequado reconhecer as implicações das acepções da ideologia tanto no campo epistemológico quanto no campo sociológico? A ideologia pode ganhar uma função social emancipatória, que decorre de uma aproximação da realidade material? Ou prevalecerá o significado negativo de distorção, contributo da alienação?

Löwy (2000) sustenta que em Marx o conceito de ideologia aparece como falsa consciência, concepção idealista na qual a realidade é invertida. Mas adverte que o mesmo Marx, em obras tardias, afirma que as ideologias podem assumir formas desveladoras, formas de consciência sobre o real. Porém o autor enfatiza que o que prevalece em Marx, operativamente, é o sentido negativo, de falsa consciência. Althusser (1980) defende a tese de que as ideologias são partes fundamentais das condições de produção para que uma dada formação social se estabeleça historicamente.

O caráter sociológico da ideologia passou a ser discutido com base na teoria de luta de classes e na relevância que a consciência de classe teria na história. Disto decorre que:

Os momentos ideológicos não "acobertam" somente os interesses econômicos, não são somente as bandeiras e as palavras-de-ordem de combate. São parte integrante e os próprios elementos da luta real. (...) Agora a luta social se reflete em uma luta ideológica para a consciência, a revelação

revista brasileira educação ambiental 
ou a dissimulação do caráter de classe da sociedade (LUKÁCS, 2014, p. 11).

A crítica da ideologia passou a considerar a expressão ideológica como um campo de disputa de subjetividades fortemente ancoradas nas objetividades prementes nas relações materiais, para além de seu caráter de falsidade. Vaisman (2010) esclarece que só no momento de sua concretização no seio da sociedade é que um determinado enunciado pode ser considerado como ideológico, ao se tornar veículo teórico/prático, constitui-se como préviaideação e concretização da prática social dos homens. O ser social é "um ser prático que reage às demandas postas pela realidade objetiva, um ser prático que trabalha a natureza como resposta a necessidades determinadas (op. cit. p. 46)". O homem, ou o ser social é caracterizado por seu potencial de dar respostas a alternativas que the são colocadas pela realidade objetiva.

Acompanhando a divisão social do trabalho e a luta de classes, o surgimento de pores teleológicos secundários mediam as relações entre os homens. A ideologia, em sua função de consciência prática expressa estes pores teleológicos secundários frente à tomada de decisões sobre uma miríade de alternativas. A educação crítico-socialista pode, portanto, formar sujeitos sociais a partir de um corpo de conhecimentos críticos (conteúdos nucleares) acumulados ao longo da história da humanidade, para que estes mesmos sujeitos reconheçam estas alternativas e, criticamente, optem pela emancipação individual, porém voltada ao interesse da coletividade. Ao educador convém estar também consciente do caráter práxico das ideologias, do seu potencial oclusivo, conservador, subversivo ou emancipador.

\section{Aspectos metodológicos}

A ação pesquisada (TRIPP, 2005) foi a abordagem (tipo) de pesquisa que viabilizou a implementação da práxis de ensino (ação interventiva) proposta pela presente pesquisa. A intervenção desenvolvida foi concretizada com a meta de teorizar sobre um processo de ensino crítico e emancipatório que buscou promover uma aprendizagem profunda da complexa rede de objetivações que compõe a relação ser humano-natureza sob o modo de produção capitalista.

A pesquisa de campo junto à turma de estudantes foi composta pelos procedimentos de observação sistemática, de entrevista semiestruturada de grupo focal e de análise documental. A intervenção, por meio de uma práxis pedagógica (sequência didática), promoveu uma ação pesquisada junto a uma turma de 20 estudantes da disciplina "O professor e o ensino da Química", componente curricular do curso de Licenciatura em Química da Ufba. Segundo Lichtman (2010), o propósito de entrevistar grupos focais é obter informações de um grupo de pessoas sobre um tópico de interesse. O que mais caracteriza o grupo focal é que em grupo a interação entre os participantes pode fazer 
emergir aspectos, pontos de vista e ideias por meio de discussões, o que não aconteceria em entrevistas individuais.

A práxis de ensino (sequência didática), seu planejamento e estruturação foi concebida pelo pesquisador com colaboração do docente da disciplina. A práxis focou na identificação e compreensão das ideologias historicamente construídas pelos estudantes, as quais foram analisadas por meio de inferências emergentes da análise de conteúdo das mensagens contidas nas entrevistas realizadas nas semanas iniciais da disciplina. A entrevista semiestruturada foi realizada durante as três primeiras semanas de aula, mas o procedimento de observação foi efetivado ao longo de toda a duração da disciplina. Durante a implementação da práxis e durante todo o restante da disciplina foram utilizados os seguintes procedimentos de coleta de dados: conversa casual, observação livre, observação sistemática e análise de documentos. Os dados foram registrados por meio de anotações em caderno de bordo. Um estudo dirigido com questões dissertativas, resenha sobre filmes e sobre textos foram objeto de análise documental (CRESWELL, 2012).

A análise dos dados foi realizada mediante elementos da técnica de análise de conteúdos. A análise de conteúdo foi empregada tanto na análise dos textos gerados nas entrevistas, quanto dos documentos dissertativos produzidos pelos alunos durante as aulas. De acordo com Bardin (2009, p. 40) "a análise de conteúdo é um conjunto de técnicas de análise de comunicações que utiliza procedimentos sistemáticos e objetivos de descrição do conteúdo de mensagens". As inferências foram realizadas de forma independente da frequência das emissões vocais, concentrando-se apenas no processo de interpretação dos significados destas emissões. A unidade de análise não foi fixada previamente, o pesquisador optou por analisar trechos do discurso dos estudantes que se apresentaram como unidades que contemplavam ideias (ideologias) que faziam sentido no contexto de elaboração da fala. Como a teoria da ideologia embasou transversalmente esta pesquisa, não foi realizada a tradicional categorização. Procedeu-se a análise do conteúdo ideológico das falas em relação à ação social presumida dos entrevistados, pois se assumiu que ideologias são conjuntos de ideias que dão sentido à prática social e que são por ela moldadas.

A análise de conteúdo também foi utilizada para deduzir e inferir sobre o conteúdo dos documentos produzidos pelos estudantes (resenhas, trabalhos, resumos). As anotações realizadas a partir da conversa casual, observação livre, observação sistemática serviram para enriquecer a descrição dos processos interativos (didáticos) que ocorreram na dinâmica entre professor e aluno. 


\section{Resultados e discussão}

A seguir estão expostos os resultados do estudo das ideologias realizado antes, durante e após a execução da práxis pedagógica (sequencia didática) que foi desenvolvida junto a uma turma de Licenciatura em Química, na disciplina "O professor e o ensino da Química" da Ufba. Os resultados aqui apresentados foram sintetizados com base em notas de observação e na análise de conteúdos das entrevistas, o que propiciou o enriquecimento da descrição processual da intervenção didática.

Buscou-se inicialmente obsequiar os estudantes sobre aspectos sociais, políticos e científicos (relativos a conteúdos passíveis de serem transpostos para a sala de aula) no tocante ao tema "água e suas implicações socioambientais relativas à produção de mercadorias, apropriação privada, utilização quotidiana e comportamento". Assim, intencionou-se identificar e descrever ideologias de estudantes, no tocante aos usos da água na sociedade brasileira, com o objetivo primaz de avaliar como as ideologias interferem em processos de ensino formal. Nas duas primeiras semanas da disciplina foram realizadas entrevistas com o objetivo de realizar um levantamento das ideologias dos estudantes. Durante a disciplina foram realizadas observações casual e sistemática; além de anotações em caderno de bordo sobre discussões ocorrentes nas aulas. Foi realizada também análise documental das atividades avaliativas efetuadas pelos estudantes. Posteriormente, foram realizadas entrevistas ao final da disciplina com a meta de comparar possíveis mudanças nas estruturas ideológicas dos estudantes.

Ao serem perguntados sobre o que entendem por Educação Ambiental e qual é a sua relevância na sociedade e na educação formal; os estudantes, em síntese, se referiram a aspectos relativos a comportamento inadequados, ao consumo e à responsabilização individual ou familiar. Mas realizaram críticas contundentes à limitação de projetos de Educação Ambiental que apenas tratavam de coleta seletiva de lixo ou de economia de água, quando eram estudantes secundaristas. Contudo, se posicionaram de forma crítica no que se refere, segundo eles, à maior preocupação das autoridades e do setor produtivo com a economia de recursos naturais do que com os impactos das ações humanas sobre o meio ambiente; além de se referirem à educação como estritamente passagem de informação. Como observado nos relatos a seguir:

\section{Estudante 1}

Eu acho que pelo menos o que eu tive de Educação Ambiental foi muito pouco, na escola eles ensinam mais a parte de lixo e só o lixo (é um problema grande), mas é um pedaço muito pouco, muito pequeno do que é o problema hoje em dia (...). Eu acho que se agente educasse as crianças elas iriam passar adiante esta informação. 
O tratamento contingente e limitado de problemas tão complexos foi percebido como problemático por parte dos estudantes, mesmo quando o tema envolve também impactos socioambientais cumulativos. Os aspectos comportamentalista e tecnicista em algumas expressões ideológicas foram detectados em algumas falas. Isto é problemático, pois podemos estar formando educadores que visem apenas formação de valores e mudança de comportamentos, de forma desarticulada com a totalidade da realidade histórica na qual a sociedade está inserida, o que pode redundar numa escola reprodutivista da sociedade e de ações pedagógicas excessivamente linguísticopragmáticas (LOUREIRO, 2006).

A seguir o pesquisador levantou um questionamento sobre a relação água, trabalho e sociedade. Foi construída uma situação realística, porém hipotética, na qual se buscou conhecer como os estudantes se posicionariam enquanto sujeitos sociais críticos e se buscariam transpor este evento da realidade para a sala de aula. Os estudantes foram convidados a considerar um cenário de crise econômica e alto desemprego. Além de ponderar sobre a futura implantação de uma grande empresa (do ramo têxtil, ou automobilístico, por exemplo) que iria se instalar em sua cidade ou seu bairro, ou próximo à escola onde trabalhariam. $O$ pesquisador os estimulou a considerar supostas promessas de emprego, impactos decorrentes da construção/operação da empresa e a função deles enquanto educadores.

Um dos estudantes realizou uma ponderação do tipo prós e contras, num esforço de manter um equilíbrio frente à realidade do desenvolvimento que se impõe e o que se pode, de fato, fazer enquanto cidadão. O que se percebeu é que o desemprego prepondera como fator decisivo sobre as ideologias destes futuros educadores. O desemprego imporia aos sujeitos sociais uma condição de imobilidade social. Demonstraram preocupação com o aspecto social, especialmente tanto no tocante a possíveis futuros empregos e quanto à responsabilidade social da empresa com os filhos dos empregados. A categoria desemprego, fortemente presente nas ideologias dos entrevistados, aponta para a adequada ênfase que as pesquisas da EAC e de diversos grupos marxistas de pesquisa na área da educação dão para a relação entre trabalho e educação. Infelizmente não se percebe esta categoria sendo tratada por linhas de Educação Ambiental de matizes não críticas. Questiona-se por quê?

O estudante 10 (ver a seguir) demonstrou uma visão crítica bem fundamentada ao trazer à discussão os aspectos econômicos, tributários e relativos à mão de obra como sendo necessário de serem discutidos no processo de implantação de uma empresa deste porte; além de demonstrar preocupação com a geração de resíduos e com os impactos sobre a infraestrutura urbana. Citou a necessidade de consulta pública e a possibilidade de contato direto da população com representantes da empresa. Contudo, não se detectou mesmo nesta ideologia de caráter preocupado com a complexidade da questão tratada, uma atitude que questione as questões de base que, de fato, são as desencadeadoras deste problema social. Ou seja, não foi detectada na análise das entrevistas questionamentos quanto ao 
sistema de propriedade, processo produtivo em sua relação com a demanda de recursos naturais; nem tampouco se cogitou a possibilidade de produção coletiva, economias solidárias e trabalho justo. Os relatos analisados demonstram que o mero conhecimento dos procedimentos legais de gestão ambiental ainda não confere ao educador a instrumentalização suficiente para uma práxis pedagógica crítica. Isto se confirmou nos próprios relatos dos licenciandos, quando se referiram à transposição didática dos conteúdos relativos ao tema discutido. Ao afirmar que o papel do educador é "questionar e expor", mesmo quando se quer "despertar" uma consciência crítica, os licenciandos não perceberam que 0 fato da realidade em toda sua complexidade pode (e deve) ser o conteúdo nuclear da sua práxis pedagógica. Contudo, segundo a proposta da EAC, conscientização na tradição críticomarxiana, não é qualquer "conscientização", mas uma reflexão histórica processual, que leva em conta fatores políticos, conhecimentos e valores voltados à transformação da relação entre o ser humano e natureza (TOZONIREIS, 2004).

\section{Estudante 10}

A gente tem que questionar a viabilidade econômica de qualquer indústria. Primeiro, quando uma indústria chega aqui nos países "de baixo", subdesenvolvidos, eles recebem uma série de isenções de impostos e vêm aqui em busca de mão de obra barata.(...) Vai querer saber que a fábrica vai gerar emprego, você vai ter todo mês seu dinheiro ali certo, vai melhorar de vida. Basicamente isso. Você está gerando empregos.

Do outro lado, na outra face da moeda, a gente tem: qual é o impacto da implementação desta fábrica naquele lugar, entendeu? Quando você instalar uma coisa desta dimensão, não só uma fábrica, você vai mexer com toda aquela localidade, no sentido de .... não só econômico, mas toda a infraestrutura. Aí você vai ter que ter energia elétrica, você vai produzir e gerar resíduos e a gente tem que ver a melhor maneira de tratar estes resíduos.

Outro estudante demonstrou conhecimento sobre o processo de licenciamento ambiental e de consulta pública, mas não indicou este conhecimento como um possível conteúdo a ser tratado na educação formal. Este mesmo raciocínio preponderou no relato dos outros estudantes. E a dificuldade de tratar do tema em sala de aula foi constatada no discurso de um dos entrevistados, que acabou recaindo no mesmo tratamento limitado em termos didático-pedagógicos que eles próprios haviam criticado ao responderem a pergunta anterior. Tal dificuldade é foco de preocupação da PHC, por isso mesmo que esta enfatiza tanto a prática social na qual os seres humanos produzem suas condições de existência. Deve-se, então, problematizar estas condições materiais, explicitando suas contradições, com vistas à superação das mesmas (MAIA, 2015).

Revbea, São Paulo, V. 13, № 4: 334-354, 2018. 
No argumento de outro estudante transparece a força da ideologia economicista/desenvolvimentista, como normalmente se encontra espraiada na sociedade, mesclada com enunciados ético-moralistas, afirmando que tudo se justifica se for em favor do sustento da família e do desenvolvimento da economia local. Todavia, outro estudante considerou que a qualidade de vida é fator relevante a ser levado em conta e que todos tem o direito de cobrar a responsabilidade socioambiental da empresa. Este posicionamento por parte do licenciando pode estar, subliminarmente, ligado a uma ideologia que considera a relação simplista entre produção e trabalho, deslocando do centro da análise as mútuas relações entre produção, distribuição, circulação e o próprio consumo (ZACARIAS, 2009).

Em seguida, os estudantes foram convidados a tratar da relação entre os tipos de usos da água que fazem no quotidiano e os usos que a sociedade faz da água. Esta questão foi inserida no roteiro de entrevista com o propósito de identificar traços ideológicos no comportamento dos estudantes, além de buscar identificar a noção de totalidade que os licenciandos teriam sobre o grau de complexidade com que a sociedade tem alcançado o uso de um dado recurso natural neste ponto da história.

\section{Estudante 8}

Lavar um prato, lavar uma roupa, fazer uma comida ... (...) $\boldsymbol{E}$ eu não ligava muito, e eu passei a morar sozinha e eu passei apagar minha conta. Aí isso acaba pesando mais para mim é como se a consciência me afetasse mais de como aquilo vai estar me afetando, do que aquilo estaria afetando pro mundo todo. Assim, a gente pensa muito na gente mesmo, entendeu?

No relato do estudante 8 percebe-se um forte resquício do individualismo burguês que recomenda a correção do comportamento individual, introjetando a assunção de uma consciência individual, que no somatório, acabaria por corrigir um problema que na verdade é de ordem social e histórica. O problema desta assim chamada "consciência individual" é que ela é, na melhor das hipóteses, fictícia. Como esclarece Lukács (2014), a consciência provém da sua relação com a situação de classe, no tocante à essência das contradições provenientes das contradições classistas. O aspecto comportamental, de problema teórico, passa a ser um problema prático, que influi de forma decisiva as tomadas de posição práticas da classe. Assim, a ideologia individualista deve ser foco de propostas educacionais críticas, pois fazem parte do núcleo comportamental do sujeito (no sentido genérico mesmo), a qual, por sua vez, encontra-se articulada com as noções burguesas de liberdade de consumo e de apropriação privada.

Interessante notar que os licenciandos demonstraram noção de que a água possui, de fato, utilidade múltipla na sociedade, inclusive no ramo industrial e no uso doméstico diário; além de citarem a economia de água no processo produtivo e seu desperdício no tratamento, muito embora não tenham

revista brasileira educação ambiental 
conseguido discernir entre as demandas do ramo industrial e do ramo agroindustrial. Todavia, se posicionaram de forma crítica quanto a propagandas na mídia que direcionam a economia de água ao cidadão sem ao menos cogitar a economia industrial. Segundo Fracalanza (2005), o essencial é discutir a forma de apropriação da água e suas transformações que decorrem de diversas atividades humanas. Como percebido nos relatos a seguir:

\section{Estudante 11}

Muito da água acaba sendo desperdiçada, a água tratada que serve à comunidade, por conta da ineficiência dos métodos de distribuição. Então a grande fatia é descartada, desperdiçada.

O estudante 10, por exemplo, tratou de fatores importantes, mas apenas relativos às condições operacionais inadequadas, não se referindo a aspectos de conservação dos mananciais, reservatórios, bacias hidrográficas, aspectos de uso/ocupação do solo e planejamento do desenvolvimento urbano. $\mathrm{Na}$ verdade, a discussão deveria se concentrar na dialética entre demanda e disponibilidade hídrica, claro, considerando toda ordem de materialidade que condiciona como a água é captada, distribuída, tratada (ou não, em muitos casos), apropriada (privatização da água) e a utilização da agua como meio de dispersão de poluentes (FRACALANZA, 2005).

$O$ aspecto técnico-prescritivo premente em determinadas ideologias, quando tocam no ponto de possíveis estratégias de solução da "crise hídrica", prevalece. Predominou indicações de soluções pontuais baseadas em correção comportamental e do consumo consciente. Isto indica que conteúdos específicos de Economia Ecologia, de Ecologia Política, de gestão de recursos hídricos seriam de grande valia, especialmente quando conjuminados aos conteúdos de Ecologia Geral, Engenharia Ambiental e de Química Ambiental, para complementar a formação de professores/educadores ambientais. Neste processo formativo, os futuros educadores devem estar conscientes da centralidade da discussão sobre políticas públicas relativas à gestão participativa (quem sabe até gestão direta) dos recursos hídricos, superando dimensões tecnicistas e questionando vieses exclusivamente capitalistas e explicitando práticas e conceitos como de valor de uso, valor de troca, economias solidárias, trabalho justo e livremente associado e acesso equitativo à água (FRACALANZA; JACOB; EÇA, 2013).

A questão seguinte, com intuito provocativo, intencionou a contextualização numa situação calamitosa (de intensa falta de água) e o tensionamento entre posicionar-se de forma autocentrada ou de forma altruísta, circunscrita ao campo das relações sociais. Foi solicitado que os entrevistados se situassem hipoteticamente em uma comunidade pobre, onde as pessoas têm dificuldade de acesso a recursos básicos, dificuldade de mobilidade, de saúde pública; e, num dado momento, a água passaria a ser racionada. $\mathrm{A}$ população desta comunidade só teria água disponível duas vezes na semana. Revbea, São Paulo, V. 13, № 4: 334-354, 2018. 
No local ainda teriam a alternativa de um poço artesiano, que funcionaria para dar apoio justamente nestes momentos. Chamou a atenção que, logo de início, um estudante fez o seguinte questionamento:

\section{Estudante 1}

Eu tenho uma pergunta: a gente quer resolver o problema na nossa casa ou na comunidade?

A seguir, o estudante expôs ter dificuldade em pensar o tema racionamento de água e deixou clara uma ideologia individualista e uma grande dificuldade de contextualizar a problemática num âmbito coletivo.

\section{Estudante 1}

Eu tenho muita dificuldade em pensar em uma falta de água, um racionamento, porque em minha casa a gente sempre teve uma cisterna. Então, mesmo aqui em Salvador, "eu nunca cheguei a faltar água em casa". Então eu não tenho nem muita noção de como seria. Mas eu imagino que num momento de crise eu tentaria usar o poço e imagino que a comunidade sabendo que existe um poço, iria virar um caos.

Outro estudante corroborou a opinião do primeiro e demonstrou-se movido pela ideologia da mercantilização e do individualismo, quando se manifesta a favor da compra de água engarrafada, mesmo que por preços exorbitantes. Não se cogitou nenhuma solução que propusesse superar a esfera individual. Quando uma possível reunião de moradores desta comunidade hipotética foi mencionada, logo foi adjetivada como uma possibilidade por demais problemática e difícil. $\mathrm{O}$ aspecto tecnicista se fez presente quando o estudante se preocupou com o volume do poço e a quantidade de água disponível para a quantidade de pessoas que a utilizam. Este pragmatismo é limitado na medida em que se concentra preponderantemente na busca de soluções imediatistas, que resultem em "soluções" ou resultados mensuráveis ou observáveis, dispensando a reflexão sobre as relações de causalidade (LAYRARGUES, 2012).

A menção a um poço artesiano foi inserida de forma proposital na questão. $A$ intenção real era trazer um aspecto minimamente referente à esfera coletiva. De forma ideal, considerando a formação de professores críticos, o poço artesiano seria mais um fator da realidade a ser considerado, mas não de forma central. Num processo formativo crítico-dialético, se esperaria discussões a cerca de políticas públicas de gestão de recursos hídricos e de saneamento básico, discutidas de forma cientificamente fundamentada. Neste processo se está à busca da formação de sujeitos que consigam "interpretar os nexos entre sociedade e ambiente e da Educação Ambiental como mediadora 
na construção social de novas posturas" (CARVALHO, 2006, pp.79-80), posturas críticas e interpretativas.

Isto não quer dizer, evidentemente, que aos futuros educadores não seja necessário dominar conteúdos importante relativos às ciências naturais. Por isso a pergunta seguinte foi bem direta: o que você entende por crise hídrica?. A seguir pode-se observar uma explanação bem interessante.

\section{Estudante 2}

Em parte eu concordo com ela. Acredito que a distribuição de água é política, econômica. (...) Então, quando você fala em racionar (crise hídrica), você está falando de crise hídrica onde? Em que região? Pra quem? Quem é que tem que racionar? Quem é que tem que ficar sem água? Então são estas questões. Por isso que eu digo que a distribuição ela é política, econômica e geográfica.

Falou-se inicialmente de regiões em que a seca é tomada como sinônimo de crise hídrica. Demonstram preocupação com o acesso à água em determinadas regiões e com a má distribuição da água. A crise hídrica também é qualificada como preponderantemente política e econômica, distinguindo as relações de poder como um determinantemente influente. Os licenciandos demonstraram-se bastante críticos ao elegerem aspectos políticos e econômicos, para além dos fatores hidrogeológicos e climáticos. Todavia, a crise hídrica deve ser tratada pela EAC como um problema que realmente sintetiza múltiplas determinações. Ou seja, se o governo e as corporações determinam a distribuição e o uso da água, cabe também questionar o mau planejamento da ocupação do solo em grandes cidades em plena expansão geográfica (e produtiva), quem ganha com isso e como isto afeta o ciclo hidrológico e o clima. O componente político é parte intrinsecamente constituinte da educação porque os conhecimentos socializados (ou que deveriam ser) fazem parte de um contexto social e político, do qual a escola, a família, o ambiente de trabalho e os sujeitos sociais fazem parte. Se o saber técnico é parte do controle que a sociedade submete o sujeito social, por outro lado, o conhecimento técnico-científico pode formar um individuo mais consciente de si e mais qualificado para intervir de forma crítica na sociedade (LOUREIRO, 2008).

Os estudantes foram então convidados a falar sobre poluição hídrica. Mais uma vez foi construída uma situação realística em que um suposto acidente de vazamento de poluentes ocorreu e uma indústria foi responsabilizada. $\mathrm{O}$ Estado então resolve aumentar substancialmente $\mathrm{o}$ valor da tarifa de água e de tratamento de esgoto em função deste evento. A questão tratou também sobre como eles, enquanto educadores, mediariam este problema em sala de aula. Esta mediação é importante porque a práxis educativa sempre tem que estar organicamente relacionada com a realidade, com a atividade social. O problema levantado foi intencionalmente limítrofe, ou Revbea, São Paulo, V. 13, № 4: 334-354, 2018. 
seja, parece, a princípio, absurdo este tipo de cobrança arbitrária. Na verdade, a intenção foi estimular os entrevistados a se posicionarem eticamente frente a uma questão socioambiental na qual ideologias prementes frequentemente afloram, seja no discurso, seja por meio de ações sociais; na maioria dos casos por ambos os meios.

\section{Estudante 8}

Então é assim: se agente for levar para o lado ecológico, pagar não é a solução. Entende: Pagar não é a solução, porque a gente não vai conseguir recuperar aquilo. Eu vou pagar a multa, mas eu não vou revitalizar o rio imediatamente, então o dano ambiental vai estar sempre ali.

Segundo a estudante entrevistada, mesmo quando se paga a multa, o dano ambiental seria irreversível; além de citar o aspecto ético, quando um valor indevido é cobrado à sociedade. Outro entrevistado apontou o princípio do poluidor-pagador e disse que a principal questão é a oposição entre a economia e a questão ambiental. E foi além, apontando impactos no sustento das famílias e a irreparabilidade do dano ambiental. Assim, os estudantes estão, em certa medida, cientes da complexidade da questão tratada. Contudo, conceber a questão de forma dialética lhes é inviável, por isso expõem dicotomias idealizadas e vicissitudes da relação entre o Estado e o setor produtivo, sem estarem conscientes de como se dá as interações entre estes complexos. Concordam que pagar não é a solução, mas não propõem uma abordagem que supere a resolução contingente do fato problemático, expressando um posicionamento ideológico típico de abordagens pragmáticas.

Até aproximadamente a nona semana de disciplina foi possível elaborar uma perspectiva geral predominante sobre as ideologias dos estudantes. Ideologias como: consumismo, produtivismo, mercadorização, inesgotabilidade dos recursos praticamente não foram identificadas no discurso dos estudantes. Contudo, o tecnicismo/pragmatismo se fez presente de forma predominante, ao lado, mas com menor importância, do utilitarismo e do individualismo.

Estas ideologias foram também identificadas na análise das sequencias didáticas elaboradas pelos estudantes com vistas à avaliação final da disciplina e na entrevista que foi realizada ao final da mesma. Como veremos a seguir.

Devemos recordar que, à luz da $\mathrm{PHC}$, no retorno à prática social, a práxis deve estar mais elaborada através dos conhecimentos sistematizados que permitiram a síntese em questão. Aqui o olhar sobre o contexto está mais impregnado de saberes científicos, na busca de nexos e significados do real. Nesta fase, reconhece-se que professor e o estudante modificaram-se intelectual e qualitativamente em relação a suas concepções sobre o conteúdo que reconstruíram, passando de um nível de menor compreensão científica para um nível de maior cientificidade da explicação da realidade, dentro de uma vertente crítico-dialética. Neste ponto de chegada, tanto o professor, 
quanto o estudante, são novos sujeitos do ponto de vista epistemológico. Os alunos não se encontrariam mais com um pensamento sincrético frente aos conhecimentos relacionados ao problema posto pela prática social no início do processo de ensino e o professor superou a sua síntese precária; agora, professor e estudante possuem um pensamento sintético, mas diferente, pelo teor desta síntese (PINHEIRO, 2016).

A seguir estão expostos os resultados da análise de conteúdo da entrevista final que foi realizada com os grupos focais.

A pergunta inicial buscou saber o que os estudantes entendem por Educação Ambiental, tanto no que se refere à sua relevância social, quanto na educação formal (na escola). Percebeu-se que os estudantes articularam à suas respectivas respostas questões políticas, sociais e econômicas. Provavelmente em função dos textos lidos que tratavam do fator econômico e social como fundamentalmente entrelaçado com as questões ambientais. Como pode-se observar abaixo nos relatos abaixo:

O estudante três demonstrou uma ênfase bem interessante no questionamento sobre as causas que promovem as alterações ambientais. Isto, na verdade, é essencial e é um problema debatido na literatura da EAC que expõe o grave problema de abordagens empírico-analíticas e pragmáticas, as quais acabam por se concentrar nas consequências, tangenciando-se da essência da crise socioambiental.

A questão seguinte tratou da relação água, trabalho e sociedade. Considerando um cenário de crise econômica, crise política e de desemprego. Foi solicitado que os estudantes refletissem sobre as implicações desta situação. O estudante 4 citou como preponderante as relações de poder e os interesses corporativos como sendo decisivos. Como educador, propôs "mostrar" os impactos causados pela empresa. Contudo, nenhum entrevistado mencionou propostas de discussão sobre políticas de gestão ou a participação da escola em colegiados de gestão ambiental que possivelmente promoveria uma aproximação mais ativa da realidade socioambiental. É importante salientar que um dos textos lidos durante o semestre tratou da gestão dos recursos hídricos, problematizando a relevância da participação social no controle da gestão pública.

\section{Estudante 2}

Se tivesse desemprego no local, aí a empresa seria bem apoiada, a instalação dela no local. Justamente porque teria uma mudança no meio ali, no local, e geraria mais renda e que, em consequência, as pessoas poderiam consumir mais. Por outro lado, pensando não só no fator econômico, mas também na questão ambiental: teria que ser fiscalizado se as empresa gera seus resíduos corretamente. $E$ isso mais uma vez teria que ser exigido pela população local, para que ocorresse de maneira correta, não prejudicando o meio e o local que elas habitam. 
O estudante 2 permaneceu numa abordagem empírica e pragmática, relacionando a necessidade da geração de renda para a subsistência das pessoas e prescrevendo a fiscalização da geração de resíduos como uma solução possível.

Uma questão importante foi a que tratou dos usos da água. $O$ pesquisador enfatizou que a questão tratava não só dos usos quotidianos, mas dos usos que a sociedade faz da água. Alguns estudantes permaneceram citando apenas usos relativos à esfera individual, como banho, cocção de alimentos e lavagem de utensílios domésticos. Contudo, cerca de metade da turma citou fatores importantes sobre o uso da água por parte do setor produtivo. Esta mudança provavelmente de deveu à leitura e discussão dos textos de J.B. Foster e de G. Foladori, os quais problematizaram estas questões num sentido dialético.

A questão posterior buscou situar os entrevistados num contexto realístico de uma comunidade pobre de Salvador, onde as pessoas teriam dificuldade de recursos, dificuldade de mobilidade, em termos de saúde e de acesso à água. Todavia, num dado momento a água passaria a ser racionada. No local, os moradores teriam uma alternativa, um poço artesiano, que serviria para dar apoio justamente nestes momentos. Questionou-se: Como você procederia no sentido de evitar a continuidade desta situação de dificuldade, de calamidade?

\section{Estudante 1}

Sendo sincera: eu usaria a água do poço, mas faria um pré-tratamento. Mas, mais importante do que fazer o uso dessa água, tendo em vista a escassez, é como ela é distribuída. Enquanto a gente está tendo escassez de água, o agronegócio, por exemplo, está utilizando cerca de 80 por cento da água pra a agricultura, enquanto você tem que está tendo que fazer escassez de água utilizando água de poço, por exemplo. Então eu usaria, mas tem que rever este negócio da revisão, da distribuição da água.

Desta vez percebeu-se uma reflexão mais aprofundada, articulando aspectos relativos à escassez, distribuição desigual e utilização da água por setores da economia. Esta questão foi bem discutida durante o semestre e os estudantes demonstraram gostar muito da forma como a gestão da água foi tratada no documentário "Ouro azul", o qual articula aspectos das relações de poder prementes no nexo entre corporações (como a Coca-cola) e o Estado, no processo de apropriação privada da água, além de tratar da pobreza em regiões da África e da América Latina como decorrentes deste processo. O pesquisador, na sequencia, propôs que se discutisse "Crise hídrica".

Desta vez os estudantes se referiram mais à gestão da água, relacionando oferta, consumo e distribuição inadequada. Foi citado também especificamente o consumo industrial como um fator importante. $O$ regime de 
chuva, mesmo citado, foi colocado como um fator secundário, sendo o gerenciamento o fator decisivo.

Outra situação foi proposta pelo pesquisador. Numa situação de poluição de grande magnitude, onde numa indústria que trabalha com efluentes perigosos ocorreu um acidente ambiental, resultando em vazamento de efluentes que atingiu um rio próximo. Em função deste evento, deste acidente ambiental, o Estado então resolve aumentar substancialmente o valor da tarifa de água e repassar para a população e, além disso, diz que a população deveria poupar água. $O$ que é que vocês pensam sobre isso? Como é que vocês agiriam, não só como cidadãos, mas como educadores, frente a uma situação destas?

O aspecto óbvio foi claramente identificado pelos estudantes: o cidadão não deveria ser punido pecuniariamente por uma ação empresarial. Contudo, a verdadeira intenção da pergunta era saber como os futuros professores procederiam, enquanto educadores, frente a uma situação desta. A turma demonstrou dificuldade de compreender que situações como estas podem ser (e são) aspectos da realidade que devem ser mediados em sala de aula; mediados didaticamente, passariam assim a serem assumidos como conteúdos escolares.

\section{Considerações finais}

Um dos objetivos desta pesquisa foi desenvolver e aprimorar os procedimentos da intervenção didática com vistas a melhorar a prática corrente de ensino na formação de professores. A intervenção pode sem dúvida ser aprimorada, essencialmente na fase da leitura da prática social. Os próprios estudantes relataram problemas graves em seus bairros no tocante principalmente ao desperdício de água. Seria interessante, quando se iniciar a intervenção, apresentar a proposta da disciplina já escutando os relatos dos estudantes, os estimulando por meio de questionamentos, talvez promovendo a discussão por meio da apresentação de notícias jornalísticas, dados levantados por órgãos governamentais ou pesquisas que tratem da gestão da água.

Durante a instrumentalização, os estudantes se identificaram com os textos que discutiam a PHC, mas sentiram dificuldade na leitura dos textos de EAC e nos textos que tratavam da abordagem marxiana da crise socioambiental. Paradoxalmente, como foi constatado na entrevista final, os licenciandos demonstraram desenvolver uma perspectiva parcialmente crítica no tocante à crise socioambiental, todavia ainda não conseguiram conceber os problemas socioambientais como possíveis conteúdos a serem tratados de forma dialética em sala de aula. Isto indica que mais leituras sobre a PHC poderiam ser intercaladas com exposição de experiências didáticas (talvez por meio de seminários realizados por professores convidados) bem sucedidas no tocante ao tratamento dialético e histórico de questões socioambientais. 
Em sala de aula, durante o planejamento e a concretização da intervenção didática, buscou-se identificar e descrever ideologias de estudantes numa disciplina de licenciatura no tocante aos usos e gestão da água, considerando o contexto social dos estudantes. Posteriormente, se avaliou como as ideologias foram alteradas durante 0 processo de desenvolvimento e concretização desta intervenção didática.

Foi percebido que materiais como os filmes foram bem acolhidos pelos estudantes e que as discussões derivadas da leitura de textos científicos devem ser bem dosadas, intercaladas por reflexões sobre o contexto políticohistórico e sobre o quotidiano dos estudantes, para que assim fique mais fácil a identificação das ideologias e a construção de ideologias contra hegemônicas. Pois, o que se pretendeu foi explicitar as ideologias, para que o docente e o pesquisador reconhecessem a forma como estas se expressam na ação política dos estudantes.

Se por um lado, a premissa explícita da presente pesquisa é de que as ideologias são categorias centrais à práxis pedagógica, especialmente no que se refere ao nexo Ideologia-Educação; por outro lado, implicitamente, está enraizada a tese sustentada por Taffarel (2011, p. 259), na qual "o marxismo por trazer em si uma dada filosofia, cuja raiz é o ser humano e sua emancipação, ou seja, a filosofia da práxis; a explicação sobre o conhecimento e a crítica radical às relações sociais dos modos de produção" é essencial para a formação de docentes críticos e dialéticos.

Estamos aqui a nos referir a uma teoria educacional de transição para a superação do capital. Claro, esta teoria exige uma teoria pedagógica, que mais especificamente se refira ao currículo e à relação professor-estudante. Taffarel, com quem concordamos, enfatiza a ontologia e a história como fundamentos basilares para explicar o ser humano, tanto no aspecto individual, como nos aspectos estruturais. A ontologia marxiana permite compreender para intervir, e no processo de intervenção complementar (enriquecer) a compreensão, com vistas à superação do capitalismo, à emancipação.

Saviani (2011) explica que como teoria da educação a Pedagogia Socialista está proficuamente voltada à prática educativa que deve buscar compreender e propor soluções para a relação dialética entre estudante e educador, visando claramente orientar o processo de ensino e de aprendizagem. A intensificação da divisão social do trabalho e das desigualdades sociais são dialeticamente relacionadas à luta de classes. A escola que hegemonicamente está voltada a promover acepções ideológicas da burguesia é uma escola que está "ligada a este processo, como agência educativa ligada às necessidades do progresso, às necessidades de hábitos civilizados, que corresponde à vida nas cidades (SAVIANI, 1994, p. 09)." Busca-se formar cidadãos e cidadãs nos moldes burgueses, preparados para a cidade e para a produção.

No que concerne a desafios, outro aspecto que se impõe é a explicitação do nexo entre Educação e Ideologia. Numa importante tese, Costa (2007)

revista brasileira educação ambiental 
esclarece que este nexo só pode ser explicitado a partir da compreensão da função social da ideologia, que só pode ser percebida dentro um contexto ontológico e tendo como pressuposto o caráter fundante do trabalho em relação ao ser social. $\mathrm{O}$ autor elucida ainda um segundo aspecto que se refere às acepções ampla e restrita da ideologia, ambas centrais na composição do caráter ideológico da educação. Trata-se da acepção restrita, que se refere a um conjunto de ideações que torna consciente e operativa a práxis social do indivíduo; e a ampla, como um canal de expressão de conflitos de classes sociais. Bottomore (2012) esclarece que nos Grundrisse, Marx reelaborou sua acepção de Ideologia, e se aproxima do que Gramsci descreve como "formas ideológicas pelas quais os homens tomam consciência desse conflito e o solucionam pela luta" - em apoio de sua concepção da ideologia como a esfera superestrutural que tudo abrange, na qual os homens adquirem consciência de suas relações sociais contraditórias.

As ideologias, portanto, não tratam necessariamente de representações deturpadas, oclusivas ou errôneas da realidade. Mesmo sendo, de fato, uma totalidade que sintetiza ideias, valores, e hábitos; as ideologias estão sempre relacionadas a dados pores teleológicos que definem a ação dos indivíduos, verdadeiras ou não, instrumentalizam o ser social em sua ação política. O nexo entre Educação e Ideologia parece agora mais claro.

Concordamos com Costa (2007), quando ele se refere às práticas sociais em disputa, o pensamento se transforma num fato ideológico por meio de múltiplas mediações. Mas este fato se transmuta, se transforma constantemente à medida que estas mediações interagem e se modificam mutuamente. Claro, a educação escolar está entre estas mediações.

A realidade, segundo esta perspectiva, pode ser concebida como Lúkács (2010) a descreve, como um complexo de complexo. Estes complexos também são compostos ontologicamente por pores que em seu bojo contêm alternativas, e o ser social responde a elas. Considerando o contexto social e esta intrincada rede de escolhas, o ser social pode decidir. Contudo esta decisão será limitada pela realidade material, pela luta de classes (e por relações de poder dela derivadas), pela alienação e pela consciência critica (considerando suas limitações e potencialidades) que este indivíduo possuirá de como suas ações venham a repercutir num dado complexo da realidade.

A Pedagogia Socialista e sua escola única voltada à formação do ser social omnilateral, deve propor o desenvolvimento do gênero humano, e isto pressupõe indivíduos cada vez mais ricos em objetivações, que reproduzem e enriquecem o gênero humano com novas objetivações. Este enriquecimento do gênero humano requer posições teleológicas conscientes que, por sua vez, dependem de ideologias voltadas à práxis social emancipatória explicitadora dos conflitos entre sociedade e natureza. 


\section{Referências}

ALTHUSSER, L. Ideologia e aparelhos ideológicos do Estado. Lisboa: Presença/Martins Fontes, 1980.

BARDIN, L. Análise de conteúdo. Lisboa, Portugal; Edições 70, LDA, 2009.

BOTTOMORE, T. Dicionário do pensamento marxista. Rio de Janeiro: Jorge Zahar Editor, 2012.

CARVALHO, I. C. M. Educação Ambiental: a formação do sujeito ecológico. São Paulo: Cortez, 2006. In: CRESWELL, J. W. Projeto de pesquisa. Porto Alegre: Artmed, 2007.

COSTA, G. M. da. Individualidade e o suposto subjetivismo da categoria alienação em Lukács. In: BERTOLDO, E; MOREIRA, L. A. L; JIMENEZ, S (Orgs.). Trabalho, educação e formação humana frente à necessidade histórica da revolução. São Paulo: Instituto Lukács, 2012.

FRACALANZA, A. P; JACOB, A. M.; EÇA, R. F. Justiça ambiental e práticas de governança da água: (re) introduzindo questões de igualdade na agenda. São Paulo, Ambiente \& Sociedade, v. 16, n. 1,. 2013.

FRACALANZA, A. P. Água: elemento natural ou mercadoria. Uberlândia, Sociedade e natureza, v. 17, n. 33, 2005.

LAYRARGUES, P. P. Muito além da natureza: Educação Ambiental e reprodução social. In: LOUREIRO, C.F.B.; LAYRARGUES, P.P; CASTRO, R.C. de (Orgs.). Pensamento complexo, dialética e Educação Ambiental. São Paulo: Cortez, 2006.

LAYRARGUES, P. P. Para onde vai a Educação Ambiental? o cenário políticoideológico da Educação Ambiental brasileira e os desafios de uma agenda política crítica contra-hegemônica. Revista Contemporânea Educação. n. 14, agosto/dezembro de 2012.

LICHTMAN, M. Qualitative research in education: a user's guide. California: Sage, 2010.Lichtman (2010)

LOUREIRO, C. F. B., TREIN, E; TOZONI-REIS, M. F. de C., NOVICKI, V. Contribuições da teoria marxista para a Educação Ambiental crítica. Campinas, Cad. Cedes, v. 29, n. 77, 2009.

LOUREIRO, C.F.B. Crítica ao fetichismo da individualidade e aos dualismos na Educação Ambiental. Curitiba, Educar, , n. 27, 2006.

LOUREIRO, C.F.B. Educação Ambiental e Movimentos Sociais: reflexões e questões levantadas no GDP. Pesquisa em Educação Ambiental, vol. 3, n. 1, 2008.

LÖWY, M. Ideologias e ciência social: elementos para uma análise. São Paulo: Cortez, 2000. 
LUKÁCS, G. Prolegômenos para uma ontologia do ser social: questões de princípios para uma ontologia hoje tornada possível. São Paulo: Boitempo, 2010.

LUKÁCS, G. Consciência de classe. Fonte: The Marxists Internet Archive. Acesso em: jul., 2014.

MAIA, J. S. S. Educação Ambiental crítica e formação de professores. Curitiba: Appris, 2015.

MARX, K; ENGELS, F. A ideologia alemã. Lisboa: Editorial “Avante!”, 1982.

PINHEIRO, B. C. S. Pedagogia histórico-crítica na formação de professores de ciências. Curitiba : Appris, 2016.

SALA, M. Alienação e emancipação na transmissão do conhecimento escolar: um esboço preliminar. In: MARTINS, L. M; DUARTE, N. (Orgs.). Formação de professores: limites contemporâneos e alternativas necessárias. São Paulo: Cultura Acadêmica, 2010.

SAVIANI, D. O trabalho como princípio educativo frente às novas tecnologias. In: Novas tecnologias, trabalho e educação. Petrópolis /RJ : Vozes, 1994.

SAVIANI, D. Educação: do senso comum à consciência filosófica. Campinas: Autores Associados, 2011.

TAFFAREL, C. N. Z. Marxismo e educação: contribuição ao debate sobre a teoria educacional e a transição. Campinas, Revista HISTEDBR On-line, número especial, 2011.

TOZONI-REIS, M.F. C. Educação Ambiental: natureza, razão e história. Campinas, SP: Autores Associados. 2004.

TRIPP, D. Pesquisa-ação: uma introdução metodológica. São Paulo, Educação e Pesquisa, v. 31, n. 3, 2005.

VAISMAN, E. A ideologia e sua determinação ontológica. Rio de Janeiro, Verinotio: revista on-line de educação e ciências humanas. n. 12, 2010.

ZACARIAS, R. "Sociedade do consumo", ideologia do consumo e iniquidades socioambientais dos atuais padrões de produção e consumo. In: LOUREIRO, C. F. B.; LAYRARGUES, P. P; CASTRO, R. S. de. Repensar e Educação Ambiental: um olhar crítico. São Paulo: Cortez, 2009. 